\title{
AVALIAÇÃO DA ATIVIDADE FOTOCATALÍTICA E ANTIFÚNGICA DE TINTAS INTELIGENTES
}

\author{
J. C. SAPATIERI ${ }^{1}$, V. Z. BALDISSARELLI ${ }^{1}$, R. F. P. M. MOREIRA ${ }^{1}$ \\ ${ }^{1}$ Universidade Federal de Santa Catarina, Departamento de Engenharia Química e \\ Engenharia de Alimentos
}

E-mail para contato: joicesapatieri@gmail.com; regina.moreira@ufsc.br

\begin{abstract}
RESUMO - Quando irradiadas com luz, na presença de ar e umidade, o fotocatalisador $\left(\mathrm{TiO}_{2}\right)$ contido na formulação das tintas inteligentes media a formação de radicais livres oxidantes, que reagem com poluentes e qualquer substância orgânica em sua superfície. Ao mesmo tempo que desenvolve a função de autolimpeza, as nanopartículas de $\mathrm{TiO}_{2}$ podem degradar as resinas poliméricas das tintas, resultando em sua autodegradação. Entretanto, é possível reduzir a autodegradação da tinta, ajustando o percentual mássico de $\mathrm{TiO}_{2}$. Este trabalho tem como objetivo produzir filmes de tintas fotocatalíticas dopadas com 5 e $10 \%$ $(\mathrm{m} / \mathrm{m})$ de $\mathrm{TiO}_{2}$ e avaliar a atividade fotocatalítica sob luz visível e UVC, além de avaliar sua atividade fungicida. Os resultados mostraram elevada atividade fotocatalítica e antifúngica, resultando na formação de um halo de inibição do crescimento do fungo Monascus ruber, típico de materiais que produzem biocidas que se difundem no meio de cultivo.
\end{abstract}

\section{Introdução}

As tintas inteligentes vêm ganhando espaço no mercado nos últimos anos, pois além das funções de proteção e decoração, apresentam elementos de alta tecnologia com a função de remover poluentes presentes na sua superfície. Essas tinta contém, além dos componentes usuais, partículas de fotocatalisadores $\left(\mathrm{TiO}_{2}\right.$ ou $\left.\mathrm{ZnO}\right)$ que promovem a geração de radicais livres oxidantes na presença de oxigênio, umidade e luz (BAUDYS et al., 2015).

As tintas de composição orgânica normalmente apresentam os melhores resultados de atividade fotocatalítica para degradação de poluentes orgânicos quando comparadas às tintas minerais devido à menor quantidade de $\mathrm{CaCO}_{3}$ e sulfato de potássio (TRYBA et al., 2015). Entretanto, a presença do fotocatalisador pode provocar a degradação das resinas orgânicas poliméricas da tinta, o que reduz sua vida útil. Por isso, o desenvolvimento de tintas autolimpantes parece ser paradoxal, uma vez que ao ser irradiado o $\mathrm{TiO}_{2}$ produz espécies altamente oxidantes que, além de degradar os poluentes presentes na superfície do filme, também são capazes de atacar a matriz polimérica provocando a degradação da própria tinta (BAUDYS et al., 2015; AMORIM, 2017). Essas reações complexas provocam alterações macroscópicas visíveis nos filmes de tinta como esfarelamento, rachaduras, formação de bolhas, alteração de cor e a emissão de componentes voláteis (WOJCIECHOWSKI et al., 
2015; VAN DRIEL et al., 2017).

NGUYEN et al. (2016) verificaram que, em pequenas concentrações, a degradação polimérica dos filmes de tinta pode ser reduzida, mas acima de $4 \%$, o $\mathrm{TiO}_{2}$ pode acelerar a corrosão e autodecomposição da tinta sob luz UV. Nesse contexto, o objetivo deste trabalho foi estudar o efeito fotocatalítico e antifúngico de tintas acrílicas contendo diferentes percentuais de $\mathrm{TiO}_{2}$ em sua formulação $(0 ; 5$ e $10 \% \mathrm{~m} / \mathrm{m})$.

\section{Materiais e métodos}

\subsection{Preparação das tintas fotocatalíticas}

As tintas fotocatalíticas foram preparadas através da adição de $5 \%$ e $10 \%$ de $\mathrm{TiO}_{2}$ (P25, Evonik) em massa sendo as duas bases de tintas fornecidas por uma indústria de tintas do Estado de Santa Catarina, conforme descrição da Tabela 1. $\mathrm{O} \mathrm{TiO}{ }_{2}$ foi adicionado à base, e com auxílio de um agitador mecânico homogeneizou-se à por aproximadamente 30 minutos.

Tabela 1: Descrição das tintas fotocatalíticas

\begin{tabular}{|c|c|c|}
\hline Amostra & Tinta & Quantidade de $\mathrm{TiO}_{2} \mathrm{P} 25, \%$ \\
\hline TS0 & Semibrilho & 0 \\
\hline TA10 & Acetinada & 10 \\
\hline TS5 & Semibrilho & 5 \\
\hline TS10 & Semibrilho & 10 \\
\hline
\end{tabular}

\subsection{Preparação dos corpos de provas}

Foram preparadas amostras de cimento de aproximadamente $4 \mathrm{~cm}^{2}$. As superfícies das s mesmas foram previamente lixadas para nivelar e cobertas com duas camadas de tinta fotocatalítica. $\mathrm{O}$ tempo de secagem entre cada camada foi de 1 hora o tempo de secagem final foi de 24 horas..

\subsection{Avaliação da degradação fotocatalítica do azul de metileno sobre UVC}

A determinação da atividade fotocatalítica foi realizada utilizando os corpos de prova pintados com as diferentes tintas e uma solução contendo azul de metileno. As superfícies dos corpos de prova com tinta fotocatalítica receberam duas camadas de solução aquosa de azul de metileno $\left(1 \mathrm{~g} \mathrm{~L}^{-1}\right)$ com auxílio de um pincel, o tempo de secagem entre cada camada foi de 1 hora e o tempo de secagem final de 24 horas.

Os corpos de prova recobertos com as tintas (TA10, TS5 e TS10) e a solução de azul de metileno foram expostos à luz UVC $(8 \mathrm{~W})$ em uma câmara escura mantendo-se a distância fixa entre a lâmpada e os corpos de prova em $10 \mathrm{~cm}$. Em intervalos regulares de tempo, as peças eram fotografadas e posteriormente analisadas para determinação de sua descolorização.

Para quantificar a degradação da solução de AM utilizou-se o aplicativo RGB color picker 
(http://www.colorpicker.com), através do processamento da imagem e determinação das intensidades das cores vermelho $(\mathrm{R})$, verde $(\mathrm{G})$ e azul (B). As cores são compiladas com a combinação de valores de RGB, onde cada uma dessas cores primárias recebe um valor de intensidade que pode ir de 0 a 255 e, quanto mais próximo de 255 , mais a cor se aproxima do branco.

\subsection{Avaliação da degradação fotocatalítica do azul de metileno sobre luz visível}

A superfície do corpo de prova recoberto com a tinta TS5 também foi submetida à degradação do azul de metileno sob luz visível, de forma análoga ao descrito no ítem 2.3, porém utilizando como fonte de radiação a luz solar. A avaliação da degradação do azul de metileno foi, também, determinada através do processamento das fotografias tomadas em diferentes tempos de irradiação, e processadas utilizando o aplicativo RGB color picker.

\subsection{Avaliação da atividade fungicida em corpos de cimento recobertos com tinta fotocatalítica}

Corpos de prova de cimento foram previamente preparados e recobertos com a tinta TS5. Após secas, as amostras foram colocadas na presença de microrganismo do gênero Monascus ruber, um microrganismo filamentoso utilizado como corante natural. Escolheu-se este fungo, pois é possível observar visualmente a formação ou não do halo de inibição, devido à coloração avermelhada que o fungo apresenta.

O meio de cultura usado foi o Potato Dextrose Agar (PDA). Foram preparadas de 3-5 colônias que necessitavam de 4-5 mL de meio cultura. $\mathrm{O}$ caldo (meio líquido de cultura) foi incubado a $30{ }^{\circ} \mathrm{C}$ e utilizou-se o padrão de turbidez 0,5 na escala Mc Farland, o que equivale a $1,2.10^{8}$ UFC $\mathrm{mL}^{-1}$. A preparação da escala Mac Farland e a preparação do inóculo foram feitas de

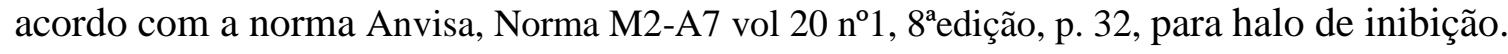

A inoculação foi realizada pelo método de pour plate em placa de Petri usando o meio adequado PDA de crescimento. Após a inoculação do fungo foi adicionada em uma das placas de Petri a amostra recoberta com a tinta TS0 e em outra a amostra recoberta com a tinta TS5. As amostras foram deixadas na estufa em temperatura de $30^{\circ} \mathrm{C}$ por 24 horas. Analisouse por cerca de 48 horas cada amostra, medindo-se o halo de inibição formado em tempos de duas em duas horas no primeiro dia e de três em três horas no dia seguinte. A variação do crescimento dos fungos foi registrada através de fotos. Este experimento foi realizado em luz visível e em câmara escura na presença de luz UVA (8W). Em todos os testes foi realizado o controle, para se comprovar que não houve contaminações.

\section{Resultados e discussões}

\subsection{Degradação do AM em corpos de prova revestidos com as tintas TS0, TA10, TS5 e TS10}

A Figura 1 mostra a evolução dos parâmetros R, G, B das tintas de base acetinada e semibrilho contendo $10 \%(\mathrm{~m} / \mathrm{m})$ de $\mathrm{TiO}_{2}$, que haviam sido recobertas com a solução de azul de metileno. Observa-se o crescente aumento em todos os parâmetros, que é típico de 
processo de descolorização. Entretanto, a tinta TSB10 resultou em valores superiores (R, G, B), indicando que a atividade fotocatalítica para degradar o azul de metileno é maior comparada a tinta TA10.

Figura 1 - Evolução dos parâmetros R, G, B dos filmes de tinta TS10 (a) e TA10 (b) recobertos com solução de azul de metileno, sob luz UVC (8W)

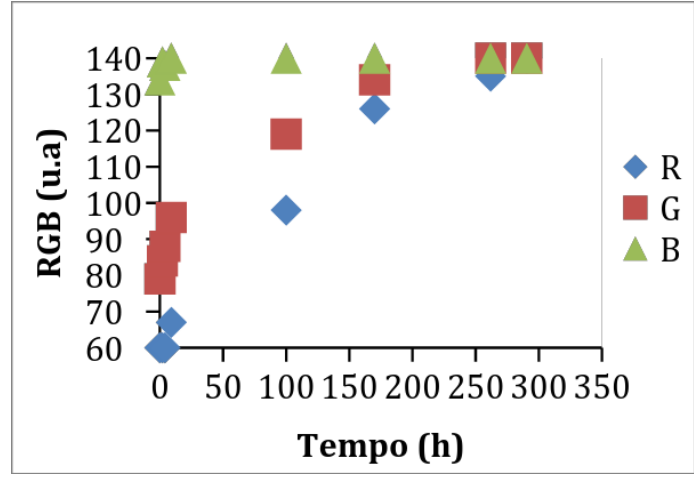

(a)

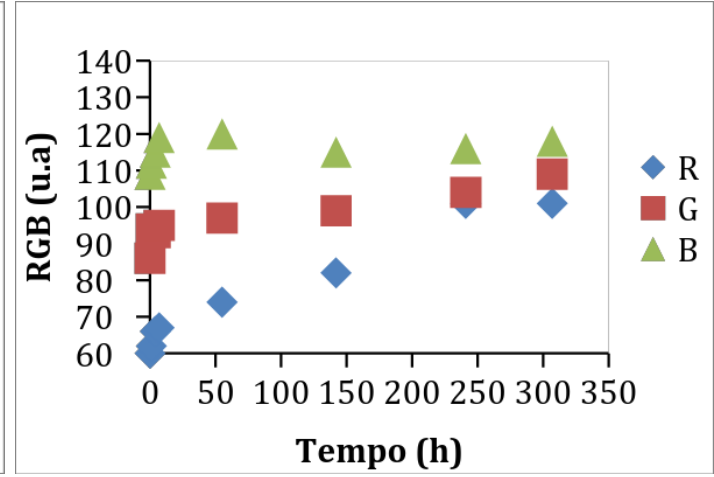

(b)

Sabe-se que, para que haja atividade fotocatalítica nas tintas as nanopartículas de $\mathrm{TiO}_{2}$ devem estar expostas à luz. Entretanto, para que isso ocorra, o filme polimérico presente na formulação da tinta deve ser parcialmente degradado, como proposto por VAN DRIEL et al. (2017). Assim, é possível que a autodegradação da tinta TS10 seja maior do que a da tinta TA10, o que expõe as partículas de $\mathrm{TiO}_{2}$ à luz, e contribui para a descolorização das peças. Uma das formas de controlar a autodegradação da tinta é a utilização de menor quantidade de $\mathrm{TiO}_{2}$ em sua formulação, sendo assim otimizou-se a concentração mássica do fotocatalisador de 10 para $5 \%$ em massa, e a comparação da atividade fotocatalítica das mesmas é mostrada na Figura 2.

Figura 2- Evolução dos parâmetros R (a) e G (b) dos filmes de tinta TS5 e TS10 recobertas com solução de azul de metileno, sob luz UVC (8W)

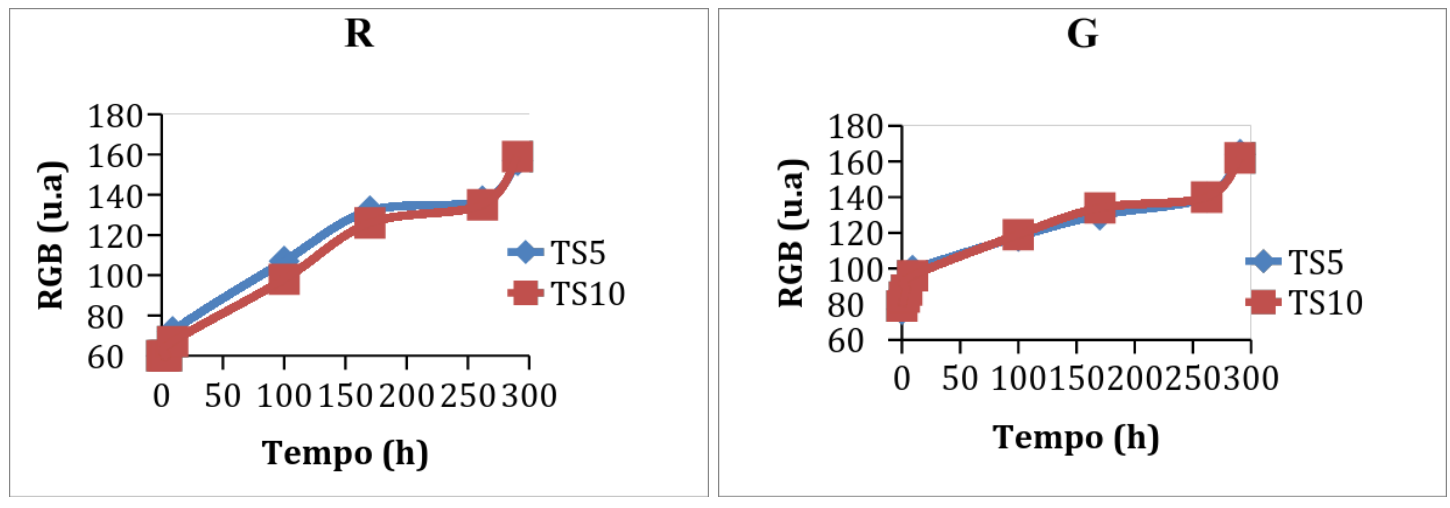

(a)

(b) 
Como mostrado na Figura 3, as tintas TS5 e TS10 provocaram descolorização do azul de metileno em extensões praticamente idênticas. De fato, como reportado na literatura (NGUYEN et al., 2016) a autodegradação da tinta deveria ser inibida somente com o uso de percentuais mássicos inferiores a $4 \%$. Por outro lado, o efeito fotocatalítico também seria reduzido, o que não é desejável.

\subsection{Descolorização de azul de metileno utilizando tintas fotocatalíticas sob luz UV e luz visível}

A comparação da descolorização do azul de metileno utilizando a tinta TS5 sob luz UV e luz visível é mostrada na Figura 4. Como esperado, a descolorização do AM é mais lenta sob luz visível, já que o $\mathrm{TiO}_{2}$ P25 é mais ativo sob luz UV do que sob luz visível (AMORIM, 2017).

Figura 3 - Descolorização de azul de metileno utilizando tintas fotocatalíticas TS5 sob luz UV (a) e sob luz visível (b)

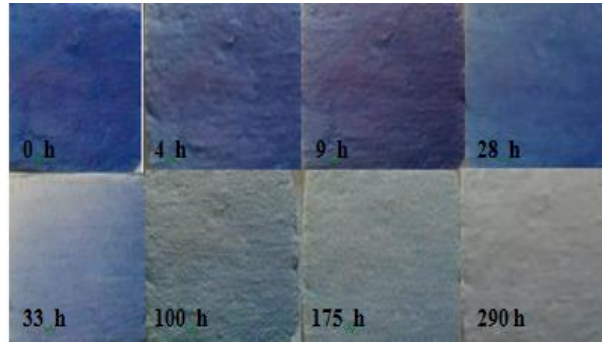

(a)

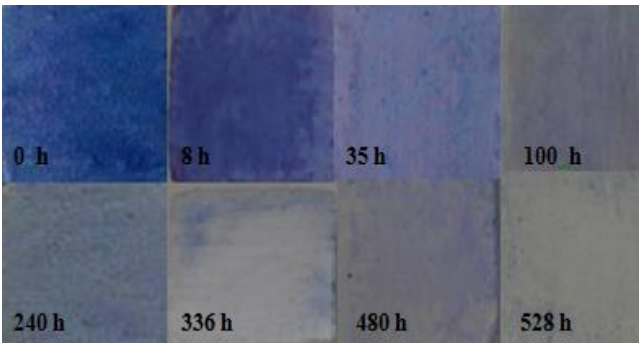

(b)

\subsection{Atividade Fungicida}

A Figura 5 mostra a formação do halo de inibição no corpo de prova revestido com a tinta TS5, e a não formação do halo de inibição no corpo de prova revestido com a tinta TS0.

Figura 4 - Visualização da formação de halo de inibição das peças pintadas com TS5 (a) e a não formação com TSO (b)

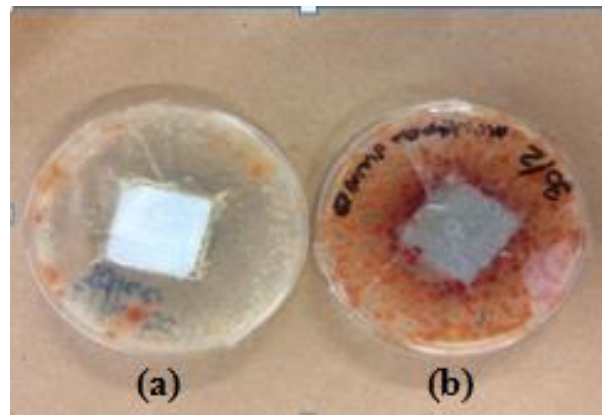

Os resultados da Figura 5 mostram a clara formação de um halo de inibição na amostra recoberta com a tinta fotocatalítica TS5, possivelmente devido à formação de radicais oxidantes como $\bullet \mathrm{OH}$ ou peróxidos capazes de migrar para a solução impedindo o crescimento dos fungos. Na amostra sem a tinta fotocatalítica, é possível observar a inibição do 
crescimento dos fungos somente em cima da peça.

É importante ressaltar que a base da tinta comercial TS0 contém fungicidas em sua formulação, conforme nota do fabricante. Entretanto, a atividade fungicida da TS0 não foi estendida para o meio do cultivo, o que ocorreu somente com a tinta contendo o fotocatalisador.

\section{Conclusões}

Pode-se concluir através dos resultados apresentados acima que TA10, TS10 e TS5 apresentaram sucesso na degradação do corante AM ao longo do tempo, o que comprova a atividade fotocatalíticas das mesmas. Entretanto, a tinta TS10 apresentou melhor atividade fotocatalítica do que a tinta TA10 e isso se deve ao fato das partículas de $\mathrm{TiO}_{2}$ estarem mais expostas à luz, possivelmente pela maior degradação da resina polimérica. Através dos resultados das atividades fotocatalíticas das tintas TS10 e TS5, pode-se observar um comportamento semelhante na cinética de degradação do corante confirmando a possibilidade de otimização da quantidade de fotocatalisador impregnado nas tintas de 10 para $5 \% \mathrm{em}$ massa. Por fim, comprovou-se a atividade fungicida das tintas através da exposição dos corpos de prova recobertos com tintas TS0 e TS5 aos microrganismos do gênero Monascus ruber. O corpo de prova recoberto com a tinta dopada de fotocatalisador (TS5) foi capaz de liberar substâncias oxidantes para o meio gerando um halo de inibição ao redor da amostra enquanto o corpo de prova com a tinta TS0 inibiu o crescimento dos microorganismos somente na superfície da tinta.

\section{Referências Bibliográficas}

BAUDYS, M.; KRÝSA, J.; ZLÁMAL, M.; MILLS, A.. Weathering tests of photocatalytic facade paints containing $\mathrm{ZnO}$ and $\mathrm{TiO}_{2}$. Chemical Engineering Journal, v. 261, p.83-87, 2015.

AMORIM, S. M. Desenvolvimento de tintas fotocatalíticas com estabilidade aumentada utilizando fotocatalisadores a base de microesferas de dióxido de titânio. Tese de Doutorado. UFSC. 2017.

VAN DRIEL, B. A.; KOOYMAND, P.J.; VAN DEN BERG, K.J.; SCHMIDT-OTTE, A.; DIKC, J.. A quick assessment of the photocatalytic activity of $\mathrm{TiO}_{2}$ pigments - From lab to conservation studio! Microchemical Journal, v. 126, p.162-171, 2016.

TRYBA, B.; WROBEL, R.J.; HOMA, P.; MORAWSKI, A.W.. Improvement of photocatalytic activity of silicate paints by removal of $\mathrm{K}_{2} \mathrm{SO}_{4}$. Atmospheric Environment, v. 115, p. 47-52, 2015.

WOJCIECHOWSKI, K.; ZUKOWSKA, G. Z.; KORCZAGIN, I.; MALANOWSKI, P. Effect of $\mathrm{TiO}_{2}$ on UV stability of polymeric binder films used in waterborne facade paints. Progress in Organic Coatings, v. 85, p.123-130, 2015.

NGUYEN, T. V.; TRI, P. N.; NGUYEN, T. D.; AIDANI, R. E.; TRINH, V. T.; DECKER, C. Accelerated degradation of water borne acrylic nanocomposites used in outdoor protective coatings. Polymer Degradation and Stability, v. 128, p.65-76, 2016.

COLOR Picker. Disponível em: 〈http://www.colorpicker.com〉. Acesso em: 15 mar. 2017.

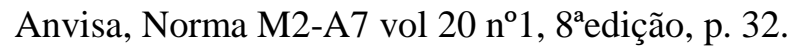

